\title{
The Moderating Effect of Technology Acceptance Perspectives on the Formation of e-SQ and Service Satisfaction in Low Cost Carrier Airline
}

\author{
Muhammad Khairi Majid ${ }^{1}$, Norhani Bakri ${ }^{1}$, Nur Shazwani Laila Junaidi ${ }^{1}$, Rahmat Roslan Buang ${ }^{2}$ \\ ${ }^{1}$ Faculty of Management, Universiti Teknologi Malaysia, Skudai, Malaysia \\ ${ }^{2}$ Quality Engineering, Universiti Kuala Lumpur, Malaysia Institute of Industrial Technology, Johor Bahru, \\ Malaysia \\ Email (corresponding author): kukhairy@yahoo.com
}

\begin{abstract}
As there is an increasing demand in public transportation and electronic transaction, the service quality of website determines the success of the service provider. Therefore, electronic service quality (e-SQ) plays an important role for any business involved in online transaction to attract customers. Customer's assessment of e-SQ is usually based on their actual experiences of interaction with the website. According to previous research, there exists relationship between e-SQ and service satisfaction. The moderating effect of technology acceptance model (TAM) shows positive result. As e-SQ and TAM improve, this will, in turn, improve service satisfaction. However, the relationship between "e-SQ-TAM service satisfactions" has been found to be not consistent in the case of low cost carrier airline in Malaysia. With concern to further understanding of this area, the present study explores dimensions of e-SQ in low cost carrier airline context and their relationship with service satisfaction. Furthermore, the moderating effect of perceived ease-of-use and perceived usefulness (TAM) was explored. This study employed convenience sampling and questionnaire method to gain data; 392 completed questionnaires were gathered from Malaysia Airline Industry (low cost carrier) website users. The result indicated that e-SQ dimensions: customization, site privacy and aesthetic, efficiency, system availability and fulfillment constitute e-SQ for low cost carrier airline. Moreover, the result also illustrates that perceived ease-of-use and perceived usefulness (TAM) positively moderate the relationship between e-SQ and service satisfaction.
\end{abstract}

Keywords: Technology acceptance model, e-SQ, Service satisfaction, Ease-of-use, Perceived usefulness

\section{Introduction}

Service industries has rapid shift in the last decade under the pressure of technology, which is creating new service, new product, new opportunities in market as well as developing more information and system oriented business. Nowadays, competitive business environment with globalization of the market and booming of internet application forces most of the organization try harder to attract and win new customers and try to maintain relationship with existing customers by giving them more satisfaction in the highly competitive electronic market (Fanaz, 2010). Airline industries players also faced such challenges (Feng-Hui, 2011).

Electronic service quality (e-SQ) plays an important role for any business that have involved in online transaction to attract customers. They can improve and create service satisfaction and fulfill customer's expectation by improving eSQ. Customer's assessment of website quality is usually based on their actual experience of interacting with the site as well as core and recovery service quality (Fanaz, 2010). Improving e-SQ nowadays can be the key advantage in 
electronic service market, therefore understanding, measuring and managing e-SQ has become significant issue to ensure customers satisfaction, loyalty and profitability.

Previous research indicated that e-SQ will affect the service satisfaction positively and translates into positive perceived service value creation (Fanaz, 2010, 2011; Fanaz et.al. 2010). Oh and Heamoon (1999) provided evidence of influential role of service quality to perceived service value and service satisfaction. As service quality improve, the probability of customers satisfaction expected to be increase, and it will reflect to increase service value perception of service exchange provided by service organization.

Previous studies on marketing point out that the key of corporate success and competitive advantage are the enhancement of service quality, perceived service value and service satisfaction (Abod Ali et.al., 2002). The formations of electronic service quality and service satisfaction has long being discussed and it is the most important research topic in service marketing literature.

Research conducted by Kuo, Wu and Deng (Ying-Feng et.al., 1989) indicated that service quality influence both perceived service value and service satisfaction. Thus, as service quality improves, the probability of service satisfaction is expected to increase, and it will reflect to increase perceived service value perception In order to satisfy and create higher perceived value to customers, service provider firm needs to offer two aspects, namely product quality and service quality.

Davis (1989) has come out with questions “what cause people accept or reject information technology?” and he found that many variables may influence system usage. Some researchers suggest that people tend to use an application to the extent that they believe it will help them perform their job better. With others words, it can be defined as perceived usefulness. Furthermore, even potential user believes that a given application is useful, but the system is too hard to use and the performance benefit of usage outweighs. Users may refuse or accept information technology inferring from its perceived ease-of-use.

Technology Acceptance Model (TAM) is one of the most used models to study individual's intention to accept or reject technology. A study conducted by previous researcher demonstrated that the effect of perceived ease-of-use and perceived usefulness plays an important role in online adaption intention.

\section{The formation of e-SQ and service satisfaction}

There is an on-going discussion in the literature about the relation and underlying difference between customer's quality perceptions and satisfaction in both traditional and internet based services. Customer's assessment of website quality and e-service quality include their experience of interacting with the site - post interaction service aspects which encompass core and e-recovery service quality. Ongoing attempts to understand the dynamics of service in online shopping context have found service quality to be related with service satisfaction as describe in figure 1.

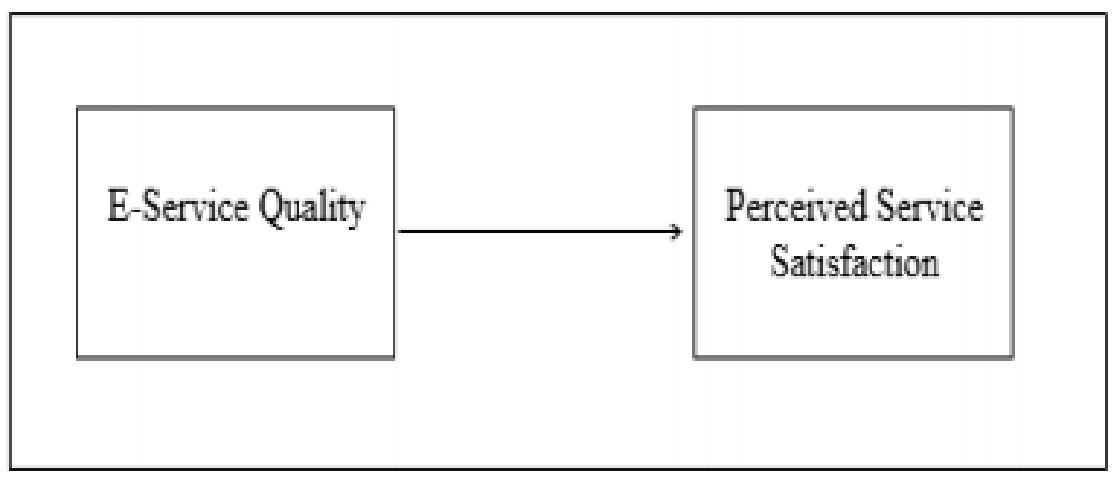

Figure 1: Relationship of E-SQ and perceived service satisfaction

Service satisfaction can be described as evaluation of an emotion. Service satisfaction refers to the degree to which customers are satisfied and pleased with their online shopping experience. Service satisfaction is driven from perceived 
quality or perceived value. Customers will compare their own service experience and expectations when they perceive fair treatment (Oliver, 1999). In order to satisfy customers, service firm needs to offer three aspects namely, product quality, service quality and price value base upon customers' expectations. In summary, it is clear that there is a relationship between service quality, satisfaction and value.

\section{TAM and its effect on the formation of e-SQ and service satisfaction}

Technology Acceptance Model (TAM) was widely used by previous researcher in studying individual intention to adopt technology. TAM was introduced by Davis (1989) to explain computer usage behavior. It assumed that perceived usefulness and perceived ease-of-use was major influence on individual attitude towards technology acceptance. Other researcher Shin (2009) showed the same findings; user attitudes and intentions are influenced by perceived usefulness and perceived ease-of-use.

Conventional TAM has suggested two beliefs; perceived usefulness and perceived ease-of-use are instruments in explaining the variance in the intention of the users. Davis (1989) encouraged examining the variance in the intention information system acceptance by extending the TAM model. While the TAM has mainly focused on explaining utilitarian information system adoption, customers' acceptance towards internet or website system might require modification and validation of the model.

Perceived ease-of-use and perceived usefulness are assumed to have an effect on the attitude in using website. Research conducted by Shin (2009) indicated that technology acceptance factor such as perceived ease-of-use and perceived usefulness influence relationship between e-SQ and service satisfaction and it is positive. Result also demonstrated that the effect of perceived ease-of-use and perceived usefulness is stronger on the relationship between e-SQ and service satisfaction.

From the logic perspective, perceived ease-of-use and perceived usefulness plays an important role in relationship between e-SQ and service satisfaction. Similarly, it is expected that relationship between e-SQ and service satisfaction in Malaysia low cost carrier airline are positively influenced by perceived ease-of-use and perceived usefulness. In order to find out this issue, it needs to be validated whether this relationship really exist in Malaysia low cost carrier airline industries.

Figure 2 shows the general framework of literature review and past research on Technology Acceptance Model (TAM).

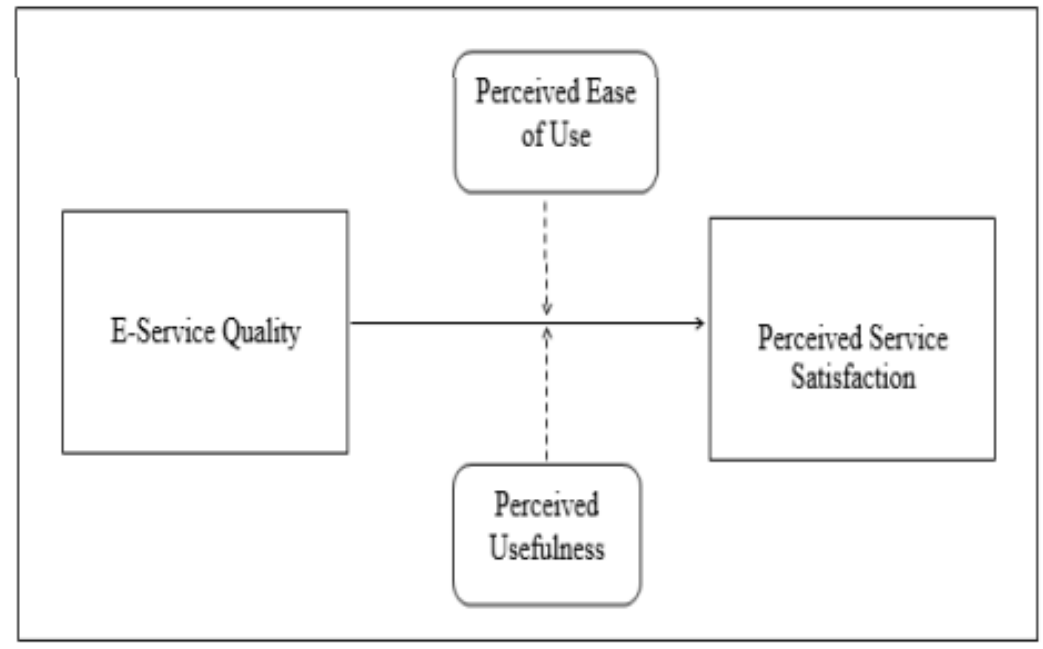

Figure 2: General research framework 


\section{Methodology}

Based on the review of e-SQ dimensions on previous research conducted in airline industries, the six dimensions of eSQ was identify to determine electronic service quality of Malaysian low cost airline carrier. The e-SQ dimension for this study was adopted and modified based on e-S-Q (Parasuraman et.al. 2005). The dimensions selected were efficiency, fulfillment, system availability and privacy. Based on literature review, other two dimensions added and modified by author were site aesthetic and customization (Feng-Hui, 2011).

Five item used for measuring Malaysian low cost airline carrier website user service satisfaction, all items were adopted based on the construct on service satisfaction purposed by Janda, Trocchia and Gwinner (Janda, 2004). In order to measure perceived ease-of-use and perceived usefulness, researcher employed TAM constructs adapted from Davis (1989 - instrument consisted of six items.

The population size for this research was the total number of Malaysian low cost airline carrier website user (international tickets holders). According to Sekaran (2004), a range of 30 as a minimum number and 500 as a maximum number of sample size is acceptable for electronic marketing surveys. Sample size required should be 5 to 10 time of variable with $10 \%$ and $5 \%$ margin error. The number of total variable in the developed questionnaire was 49 , thus a minimum of 245 questionnaires were needed with $10 \%$ margin error and 490 questionnaire were needed with $5 \%$ margin error. In this research, the researcher selected 5\% margin error. However, only 392 set of questionnaires were fully answered and completed by respondent.

\section{Result}

To examine the moderating effects of perceived ease-of-use and perceived usefulness of Technology Acceptance Model (TAM) on the relationship between e-SQ and service satisfaction, hierarchical model was used. Four regression steps - the moderating effects of TAM on the relationship between e-SQ and service satisfaction have been develop to test the moderating variable to the independent and dependent variable.

First step to perform analysis on the moderating variable (perceived ease-of-use and perceived usefulness) is test the relationship between independent variable (e- SQ) and the dependent variable (service satisfaction) by using a simple regression analysis. Regression analysis result show $\mathrm{R}$ value load was 0.813 . The value represents positive and significant relationship between variables. After the first step analysis represented significant result, analysis for TAM (perceived ease-of-use and perceived usefulness) and perceived service satisfaction was continued.

The second step continued with analysis of relationship between independent variable (e-SQ) and moderating variable (perceived usefulness and perceived ease-of-use) by using simple regression analysis. Result regression analysis present $\mathrm{R}$ value loaded between 0.822 and 0.829 and $\mathrm{P}<0.01$. These values show there is a relationship between this variable. The relationship between variables can be concluded as positive and significant.

Third step followed by testing the relationship between the moderating variable (perceived usefulness and perceived ease-of-use) with independent variable (service satisfaction) by using simple regression analysis. The result shows $\mathrm{R}$ value 0.762 and 0.866 , furthermore the entire service satisfaction dimension as independent variable is significantly correlated with the moderating variable (p 1.96). Therefore, the third condition is met where these values represent positive and significant relationship between variable. With significant value represents step 1 until 3 represent all variable have a significant relationship between independent variable, dependent variable and moderating variable. Thus, the last step which is step 4 shall be continued to analyses moderating variable between relationship independent variable and dependent variable. Step 1 until 3 represent all variable have a significant relationship between independent variable, dependent variable and moderating variable. Thus, the last step which is step 4 shall be continued to analyses moderating variable between relationship independent variable and dependent variable.

The last step in hierarchical regression model analysis would be decided whether TAM variable (perceived ease-of-use and perceived usefulness) is moderating variable between relationship e-SQ and service satisfaction. This last step 
would use multiple regression analysis in analyzing the moderating effect. In the regression analysis to test the moderator, there have three steps to follow (Aguinis, 2004; Meyers, 2006) which are:

1. Enter independent variable on first block of regression analysis

2. Enter moderating variable on second block of regression analysis

3. Enter result of independent variable multiple with moderating variable on third block of regression analysis

\subsection{Relationship between e-SQ, perceived ease-of-use and service satisfaction.}

Multiple regression analysis result (relationship between e-SQ, perceived ease-of-use and service satisfaction), show when independent variable (e-SQ) enter in first block of regression analysis R2 value loaded 0.662 it represent that $66.2 \%$ of service satisfaction dimension being explain by e-SQ and it significant. In second block when moderating dependent (perceived ease-of-use) being added R2 value increase to 0.782 it show increasing trend to $12 \%$ and it significant. Increasing R2 value 12\% on service satisfaction contributed by moderating variable (perceived ease-of-use).

Furthermore in block third block, when result of independent variable multiple with moderating variable (e-SQ X perceived ease-of-use), it show increasing value on R2 from 0.782 to 0.785 (increasing value 0.003 ) and it was significant $\mathrm{P}<0.05$. Thus, result of multiple between independent variables and moderating variable contribute $0.3 \%$ variance explained to service satisfaction. Regression analysis result represent all finding in steps 4 was significant. This result indicates that perceived ease-of-use suitable being a moderating variable between e-SQ and service satisfaction.

\subsection{Relationship between e-SQ, perceived usefulness and service satisfaction}

Referring to multiple regression analysis result of relationship between e-SQ, perceived usefulness and service satisfaction, indicated that when independent variable (e-SQ) enter in first block of regression analysis R2 value loaded 0.662 it represent that $66.2 \%$ of service satisfaction dimension being explain by e-SQ and it significant. In second block when moderating dependent (perceived usefulness) being added $\mathrm{R}^{2}$ value increase to 0.686 it show increasing trend to $2.4 \%$ and it significant. Increasing $\mathrm{R}^{2}$ value $2.4 \%$ on service satisfaction contributed by moderating variable (perceived usefulness). Furthermore, on third block when result of independent variable multiple with moderating variable (e-SQ $\mathrm{X}$ perceived usefulness), it show increasing value on $\mathrm{R}^{2}$ from 0.686 to 0.687 (increasing value 0.001 ) and it was not significant $\mathrm{P}>0.05$. Then, the multiple results of these variables (independent and moderating) only contribute $0.1 \%$ value of the service satisfaction variance.

Regression analysis result represent only first and second block was significant and the third block was not significant. This result indicates that perceived usefulness not suitable being a moderating variable between e-SQ and service satisfaction, although there is a significant relationship between e-SQ, perceived usefulness and service satisfaction.

\section{Discussion}

Many studies conducted to investigate factors that influence individuals to the acceptance of information technology. Using the technology approaches, many researchers have used different theories to test the determinant factors in specific theory that affect the information technology acceptance. There are two popular theories that have been used by the researcher in the research. The two theories are Theory of Reason Action (TRA) and Technology Acceptance Model (TAM).

Technology Acceptance Model (TAM) is one of the most used models to study individual intentions to adopted technology. Technology Acceptance Model (TAM) was introduced by Davis (1989), which described an individuals' acceptance of information technology. The objective of TAM stressed on adoption degree of a person in using a technology and aspect that affects the acceptance. TAM was the early model attempted to apply psychological factors to information system and computer adoption. It assumes perceived of use and perceived ease-of-use was the major influence of an individual's attitude toward technology (Davis, 1989).

The current study focused on investigating customer's perception of e-service quality experiences and perceived service satisfaction by applying the concept of technology acceptance perspective (perceived usefulness and perceived 
ease-of-use) to predict consumer behaviors when purchasing online tickets from a low cost carrier service provider. Having integrated the result of previous research with this study, it is evidence that perceived ease-of-use and perceived usefulness not only play a key role in predicting customers attitude towards online shopping and purchasing intention, but also in exploring the moderating role of the consumers who have experienced purchasing e-traveling service.

A study conducted by Shin (2009) demonstrated that the effect of perceived ease-of-use and perceived usefulness will be stronger on the relationship between e-service quality and e-service satisfaction. Examples of previous researcher finding was the same with this current research finding when the researcher performed analysis for the moderating effect (perceived ease-of-use and perceived usefulness) between variable (e-service quality and perceived service satisfaction), researcher also found the same finding like previous researcher dedicated on their research finding where perceived ease-of-use and perceived usefulness (TAM variable) play a positive moderating effect between dependent variable and independent variable. As the result showed $\mathrm{R}$ value for moderating effect in this study represented value between 0.762 and 0.866 , it showed there was positive and high moderating correlation between independent variable and dependent variable in this study.

As conclusion perceived ease-of-use and perceived usefulness play an important role in determining service quality and perceived service satisfaction with online adaption intention in Malaysia airline industry low cost carrier. When Technology Acceptance Model (TAM) moderated the formation of relationship between e-service quality and service satisfaction, it was found the relationship between variable in Malaysia airline industry (low cost carrier) become more positive.

Finally study focused only on conventional Technology Acceptance Model (TAM) that contained only two dimensions which were perceived usefulness and perceived ease-of-use. Therefore future studies should focus and expend on investigating the extended Technology Acceptance Model (TAM) in order to get the holistic result of moderating effect on e-service quality. The extended TAM included additional dimension of perceived credibility and computer selfefficiency that may influences how electronic consumers perceived e-SQ, perceived value and service satisfaction in low cost carrier airline.

\section{References}

- Fanaz Beheshti Zavareh, The dimension of electronic service quality for Iranian internet banking. PhD thesis,

- Feng-Hui Lee, Wann-Yih Wu, Moderating effects of technology acceptance perspective on eservice quality formation: Evidence from airline website in Taiwan. Expert system with applications 38 (2011) 77667773, Crossref

- Fanaz Behashti Zavareh, Mohd Shoki md Ariff, Ahmad Jusoh, Norhayati Zakuan, and Ahamad Zaidi Bahari, Eservice quality dimension and their effect on E-customers satisfaction in internet banking services. Procedia social and behavioral sciences, 00 (2012) 441-445, Crossref

- Heamoon, Service quality, customers' satisfaction, and customer value: A holistic perspective. Hospitality

- Management, 18(3) (1999) 67-82.

- Abod Ali Khatibi, Hishamuddin Ismail and Venu Thyagarajan, What drives customer loyalty: an analysis from the telecommunication industry. Journal of Targeting. Measurement and Analysis for Marketing 11 (2002) 34-44.

- Ying-Feng Kuo, Chi Ming Wu and Wei-Jaw Deng, The relationships among service quality, perceived service value, customer's satisfaction, and post-purchase intention in mobile value added service. Computer in Human Behavior 25 (2009) 887-896.

- Davis, F.D., Perceived usefulness, perceived ease-of-use, and acceptance of information technology. MIS Quarterly 13 (1989) 319-340, Crossref

- Oliver, R.L., Whence consumer loyalty? Journal of Marketing 63 (4) (1999) 33-34, Crossref

- Dong-Hee Shin, Towards an understanding of the consumer acceptance of mobile wallet. Computer in human

- Parasuraman et al., A. Zaithaml, Valerie, Malhotra Arvind, E-S-Qual, A Multiple-Item Scale for Assessing Electronic Service Quality; Journal of Service Research 7(3) (2005) 213-233, Crossref

- Janda, S., Trocchia, P.J, and Gwinner, K.P., Consumers perception of internet retail service quality. 
Muhammad Khairi Majid, Norhani Bakri, Nur Shazwani Laila Junaidi, Rahmat Roslan Buang The Moderating Effect of Technology Acceptance Perspectives on the Formation of E-SQ and Service Satisfaction in Low Cost Carrier

- International Journal of Service Industry Management 13(5) (2002) 412-431, Crossref

- $\quad$ Sekaran, U., Research Methods for Business, John Wiley \& Sons, United States of America, (2002). United State of America: sage publications (2006). 